\section{Palpation Techniques}

Author(s)/Editor(s): Bernhard Reichert

Publisher: Georg Thieme Verlag KG

Language: English

ISBN: 978-31-3146-342-5

Edition: 2/e

Publish Year: 2015

Pages: 464, illustrated

Price: $€ 79.99$

DOI: https://doi.org/10.25241/stomaeduj.2016.3(3-4).bookreview.7

\section{Palpation Techniques}

With the collaboration of

Wolffang Stelzenn
Omer Matthijs

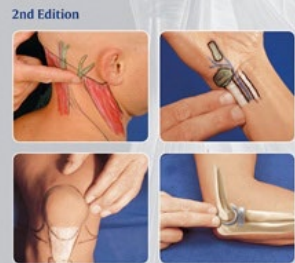

The second edition of "Palpation Techniques" provides detailed sources for anatomical, biomechanical and pathological information. The author divided the book in thirteen chapters. Chapter one covers the basic principles of surface anatomy and the characteristics of palpation. Each of the following chapters describes one region of the body at a time. The author talks about significance and function, common applications of treatment, required basic anatomical and biomechanical knowledge, local palpation of the shoulder complex, elbow complex, hand, hip and groin region, knee joint, foot, posterior pelvis, lumbar spine, thoracic spine and cage, cervical spine, and head and jaw. This revised edition is an excellent reference book for students, clinicians and therapists; it is very well presented and richly illustrated with over 800 illustrations and helps them to optimize patient care.

The Book Review is drafted in the reviewer's sole wording and illustrates his opinions.

Marian-Vladimir Constantinescu

\section{DDS, PhD}

ROPOSTURO-Holistic Dental

Medicine Institute

Bucharest, Romania

e-mail:

dr.vladimir.constantinescu@gmail.com 